\title{
Simulation of Static Flying Attitudes with Different Heat Transfer Models for a Flying-Height Control Slider with Thermal Protrusion
}

\author{
Du Chen · David B. Bogy
}

Received: 16 June 2009/ Accepted: 30 November 2009/Published online: 16 December 2009

(C) The Author(s) 2009. This article is published with open access at Springerlink.com

\begin{abstract}
The thermal flying height control (TFC), aka dynamic fly height (DFH), technique has been recently used in the head disk interface of hard disk drives to obtain a lower head-media spacing. The air bearing cooling effect, i.e., the heat conduction between the slider and the air film, has been incorporated in the numerical thermal-mechanical simulation of the slider's static performance. However, the heating effect of the viscous dissipation of the air flow has not been considered yet. In this article, both effects are included in the simulation of a flying slider with its flying height controlled by thermal protrusion, and different models for the air bearing cooling are used to obtain the slider's static flying attitudes. The simulation results directly show that the air bearing cooling is dominant compared with the viscous heating. All of the air bearing cooling models, including a recent one that considers the dependence of the air molecular mean free path on the air temperature, have simulation results close to each other. The largest relative difference in the simulated flying height is less than $9 \%$ even when the transducer flying height is lowered to below $2 \mathrm{~nm}$.
\end{abstract}

Keywords Air bearings - Thermal effects in hydrodynamics - Magnetic data recording heads . Magnetic data storage

D. Chen $(\bowtie) \cdot$ D. B. Bogy

Computer Mechanics Laboratory, Department of Mechanical

Engineering, University of California, Berkeley, CA 94720,

USA

e-mail: duchen@cml.me.berkeley.edu

Present Address:

D. Chen

Hitachi, GST, 5601 Great Oaks Parkway, San Jose, CA 95193, USA

\section{List of symbols}

$h$

$k \quad$ Thermal conductivity of the air

Kn Knudsen number

$p \quad$ Air bearing pressure

$p_{0} \quad$ Ambient (or reference) air pressure

$\mathrm{Pr} \quad$ Prandtl number

$q \quad$ Heat flux at the slider's air bearing surface

$q_{\text {conduction }}$ Conduction heat flux at the slider's air bearing surface

$q_{\text {viscous }} \quad$ Viscous dissipation at the slider's air bearing surface

$q_{\text {Couette }} \quad$ Viscous dissipation due to Couette flow at the slider's air bearing surface

$q_{\text {Poiseuille }}$ Viscous dissipation due to Poiseuille flow at the slider's air bearing surface

$q_{\text {cont }} \quad$ Conduction heat flux with the rarefaction effect neglected

$Q_{\mathrm{Ju}} \quad$ Conduction heat flux in Ju's model normalized by $q_{\text {cont }}$

$Q_{\mathrm{ZC}} \quad$ Conduction heat flux in Zhang's and Chen's models normalized by $q_{\text {cont }}$

$Q_{\text {Zhou }} \quad$ Conduction heat flux in Zhou's model normalized by $q_{\text {cont }}$

$R \quad$ Specific gas constant

$T \quad$ Air bearing temperature

$T_{\mathrm{S}} \quad$ Temperature of the slider surface

$T_{\mathrm{d}} \quad$ Temperature of the disk surface

$T_{0} \quad$ Ambient (or reference) air temperature

$U$ Linear velocity of the disk at the slider location in the slider length direction

$x, y, z \quad$ Coordinates for the air bearing in the directions of the slider length, width and height, respectively 


\section{Greek symbols}

$\alpha \quad$ Momentum accommodation coefficient

$\gamma \quad$ Ratio of the specific heat

$\lambda \quad$ Mean free path of the air

$\lambda_{0} \quad$ Reference mean free path of the air molecules at the temperature $T_{0}$ and pressure $P_{0}$

$\mu \quad$ Viscosity of the air

$\rho \quad$ Density of the air bearing film

$\sigma_{\mathrm{T}} \quad$ Thermal accommodation coefficient

\section{Introduction}

The thermal flying height control (TFC)-dynamic fly height (DFH) - technique, as presented in the patent by Meyer et al. [1], is widely used in current hard drives to lower the slider's flying height in order to achieve a higher magnetic recording density. This advantageous technique makes use of a resistance heating element near the read/ write transducer. When a current is applied through the heating element, the slider body undergoes a local thermal expansion and forms a localized thermal protrusion near the slider's trailing edge center and close to the read/write transducer. The thermal protrusion reduces the flying height very locally at the transducer. In this way the transducer flying height becomes adjustable.

The cooling effect of the air bearing flow on a slider with thermal protrusion was first numerically analyzed by Juang et al. [2]. The thermo-mechanical coupling problem between the thermal protrusion and the air bearing was numerically solved using a loop composed of a static Reynolds equation solver for the air bearing and a finiteelement analysis for the thermal protrusion. It was shown that the heat transfer from the slider to the disk through the air bearing film has a considerable effect on the flying height reduction efficiency. Their simulation work adopted a head-disk interface (HDI) heat transfer model developed by Chen et al. [3]. The viscous dissipation in Chen's model was neglected in the simulation by Juang et al., as Chen's model concluded that on the air bearing surface (ABS) the viscous dissipation is about 1-2 orders of magnitude less than the heat conduction.

Besides Chen's model, several other models have been proposed to approximate the heat transfer in the HDI. Ju [4] introduced one heat transfer model with different viscous dissipation for Couette flow, based on his simulation results with the direct simulation Monte Carol (DSMC) method. Recently, Zhou et al. [5] took the temperature dependence of the mean free path into account in the temperature jump theory and obtained a new heat conduction model. Shen and Chen [6] proposed yet another new heat transfer model by solving the linearized Boltzmann equation for the air bearing flow.
Questions naturally arise as to how important the viscous dissipation of the air film is to the slider's flying attitudes and how much difference is caused in the static flying attitude with these different heat transfer models applied in the static air bearing simulations. They are addressed here using both pico $(1.25 \mathrm{~mm} \times 1 \mathrm{~mm} \times$ $0.3 \mathrm{~mm})$ and femto $(0.85 \mathrm{~mm} \times 0.7 \mathrm{~mm} \times 0.23 \mathrm{~mm})$ air bearing slider designs with TFC in the thermal-mechanical simulation with different HDI heat transfer models. The simulation results show that the viscous dissipation has little effect on the static flying attitude even when the $\mathrm{FH}$ is less than $2 \mathrm{~nm}$. It is also found that those different models for heat conduction on the ABS produce very close simulation results for the slider's static flying attitude. The relative difference is less than $9 \%$ in the static transducer flying height and less than $1 \%$ in the pitch angle, when compared with Chen's model.

\section{Heat Transfer Models for the Head-Disk Interface}

The HDI heat transfer model developed by Chen et al. [3] originates from the model by Zhang and Bogy [7]. Zhang's model and Chen's model both use the velocity slip and temperature jump boundary conditions. Both models have shown that the heat flux on the ABS has two contributions. One is the heat conduction, which transfers heat from the slider to the air film when the ABS has a higher temperature than the disk surface; the other is the viscous dissipation due to the air flow within the HDI. For a simplified situation with disk velocity $U$ in the slider length direction (i.e., $x$-direction) and zero disk velocity in the slider width direction (i.e., $y$-direction), as shown in Fig. 1, the heat flux on the ABS in both models can be expressed in terms of,

$q=q_{\text {conduction }}+q_{\text {viscous }}=q_{\text {conduction }}+q_{\text {Couette }}+q_{\text {Poiseuille }}$,

where

$q_{\text {conduction }}=-k \frac{T_{\mathrm{s}}-T_{\mathrm{d}}}{h+2 b \lambda}$

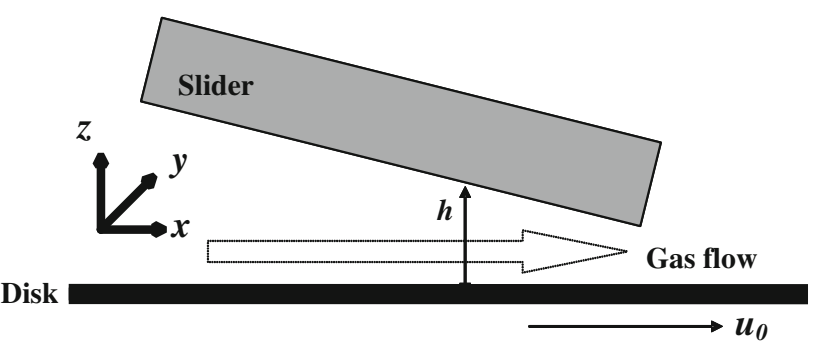

Fig. 1 Gas lubrication film in the head-disk interface between the slider and the disk 
$q_{\text {Couette }}=\frac{\mu U^{2} h}{2(h+2 b \lambda)^{2}}$.

In Zhang's model

$$
\begin{aligned}
q_{\text {Poiseuille }}= & -\frac{U h^{3}}{6(h+2 b \lambda)(h+2 a \lambda)} \frac{\partial p}{\partial x} \\
& +\frac{h^{3}}{24 \mu}\left[\left(\frac{\partial p}{\partial x}\right)^{2}+\left(\frac{\partial p}{\partial y}\right)^{2}\right],
\end{aligned}
$$

while Chen's model has

$$
\begin{aligned}
q_{\text {Poiseuille }}= & -\frac{U h\left(a h \lambda+b h \lambda+2 a b \lambda^{2}\right)}{6(h+2 b \lambda)(h+2 a \lambda)} \frac{\partial p}{\partial x} \\
& +\frac{a h^{2} \lambda}{4 \mu}\left[\left(\frac{\partial p}{\partial x}\right)^{2}+\left(\frac{\partial p}{\partial y}\right)^{2}\right] .
\end{aligned}
$$

Here, $k$ is the thermal conductivity of air; $\mu$ the viscosity of air; $T_{\mathrm{s}}$ and $T_{\mathrm{d}}$ the temperatures of the slider and the disk, respectively; $h$ the local slider-disk gap; $\lambda$ the local mean free path of air molecules; $p$ the local air bearing pressure. The parameter $b$ in Eqs. 2 and 3 can be expressed in the form of

$b=2 \frac{\left(2-\sigma_{\mathrm{T}}\right)}{\sigma_{\mathrm{T}}} \frac{\gamma 1}{(\gamma+1) \operatorname{Pr}}$,

where $\sigma_{\mathrm{T}}$ is the thermal accommodation coefficient; $\operatorname{Pr}$ the Prandtl number of air, $\gamma$ the ratio of specific heats. The parameter $a$ is expressed as $a=(2-\alpha) / \alpha$, where $\alpha$ is the momentum accommodation coefficient. For an isothermal air bearing film, the mean free path $\lambda$ is inversely proportional to the gas pressure $p$. It should be pointed out that the first term in the expression of $q_{\text {Poiseuille }}$ represents the coupling of Poiseuille flow and Couette flow. That term is included in the heat flux contributed by Poiseuille flow just for a notation simplification here. Zhang's model and Chen's model both show that the heat flux on the ABS is dominated by the heat conduction while viscous dissipation is only a second-order effect. Because of this, only the heat conduction on the ABS, i.e., the cooling effect of the air bearing, is considered in the static flying height simulation by Juang et al. [2].

Ju [4] proposed another heat transfer model for the HDI. His DSMC results validate the heat conduction part based on the temperature jump theory. However, the viscous dissipation in Ju's model is different from that shown in Eq. 1c. The viscous dissipation due to Couette flow is derived from an approximate solution to the Boltzmann transport equation, while the viscous dissipation contributed by Poiseuille flow is not included in Ju's model. The surface thermal accommodation coefficient is fixed as unity. The complete expression for heat flux on the ABS in Ju's model is,

$$
\begin{aligned}
q & =q_{\text {conduction }}+q_{\text {Couette }} \\
& =-k \frac{T_{\mathrm{s}}-T_{\mathrm{d}}}{h+\frac{4 \gamma}{(\gamma+1) P r} \lambda}+\frac{1}{8} \rho U^{2} \sqrt{\frac{8 R T}{\pi}} \frac{2 \lambda}{h+2 \lambda},
\end{aligned}
$$

where $\rho$ is the air density and $T$ the air bearing temperature. The derivation of $q_{\text {Couette }}$ is based on an assumption that the air flow is isothermal. When the temperature difference between the slider and the disk is negligible, i.e., $T_{\mathrm{s}}-$ $T_{\mathrm{d}} \ll T_{\mathrm{s}}$ and $T_{\mathrm{s}}-T_{\mathrm{d}} \ll T_{\mathrm{d}}$, the isotheral flow assumption is still valid for the air bearing. Then, $T$ can be approximated by $\left(T_{\mathrm{s}}+T_{\mathrm{d}}\right) / 2$.

As an extension to Zhang's and Chen's models, Zhou et al. [5] took into consideration the temperature dependence of the air molecule's mean free path and proposed a generalized heat transfer model. They replace the air mean free path $\lambda$ in Eq. $1 \mathrm{~b}$ with $\lambda_{\mathrm{T}}$, the air mean free path at temperature $T$. The expression $\lambda_{\mathrm{T}}=\xi\left(T / T_{0}\right)^{\omega+0.5}\left(p_{0} / p\right) \lambda_{0}$ [8] is adopted in their new model with parameters $\xi$ and $\omega$ determined by an air molecular model or experimental data of the air. Here, $\lambda_{0}$ denotes the reference mean free path of air molecules at the reference temperature $T_{0}$ and pressure $p_{0}$. Experimental data suggest $\xi=0.80-0.85$ and $\omega=0.75$ for an air film [5], while the hard sphere gas molecular model, which is used in Zhang's and Chen's models, has $\xi=1$ and $\omega=-0.5$, i.e., $\lambda_{\mathrm{T}}=\lambda=\lambda_{0} p_{0} / p$. So, it is apparent that Zhou's model can be reduced to Zhang's and Chen's models.

Different from these models based on the velocity slip and temperature jump theory, a HDI heat transfer model recently proposed by Shen and Chen [6] is derived from the solution to the linearized Boltzmann equation for the air film. This model agrees with the conduction heat part in Zhang's, Chen's, and Ju's models, but it has different viscous dissipations. However, the linearized Boltzmann equation itself predicts vanishing viscous dissipation for the air film in the HDI, which is thin and subsonic [9]. This contradicts the non-zero viscous dissipation in Shen's model.

The difference between these heat conduction models can be directly seen from the comparison between the nondimensional conduction heat fluxes given by these models. When the slider-disk separation is much larger than the air mean free path, i.e., $h \gg \lambda$, the rarefaction effect of air molecules can be neglected and the conduction heat flux is reduced to $q_{\text {cont }}=-k \frac{T_{\mathrm{s}}-T_{\mathrm{d}}}{h}$. Normalized by this heat flux, the expressions of non-dimensional conduction heat flux in Zhang's and Chen's models, Ju's model and Zhou's model can be written as,

$$
Q_{Z-C}=\frac{D}{D+\frac{22 \sqrt{\pi} \gamma \quad 1}{9(\gamma+1) P r}}
$$


Fig. 2 Non-dimensional conduction heat flux obtained from Chen's model (i.e., Zhang's model), Ju's model, and Zhou's model
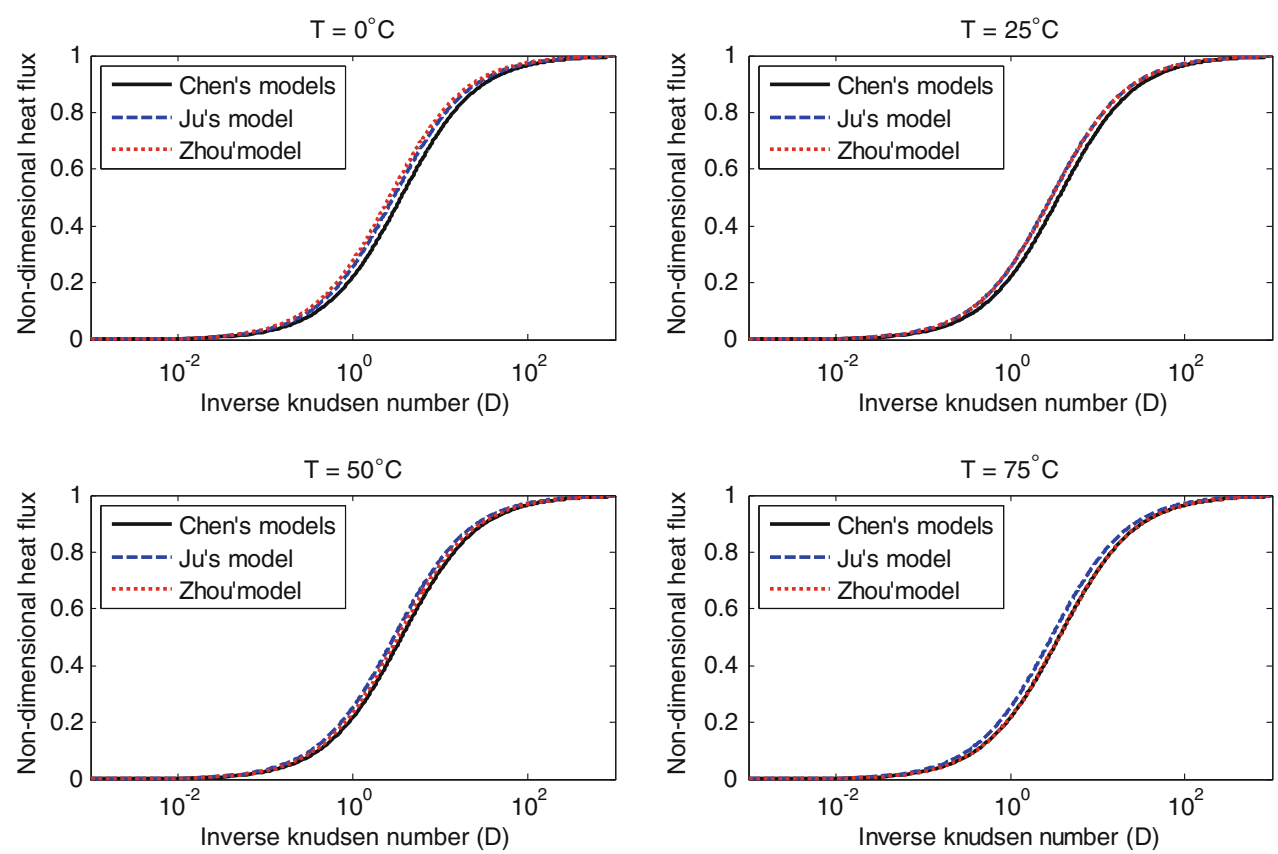

$Q_{\mathrm{Ju}}=\frac{D}{D+2 \sqrt{\pi}_{\frac{\gamma}{\operatorname{Pr}(\gamma+1)}}}$,

$Q_{\mathrm{Zhou}}=\frac{D}{D+3.5718\left(\frac{T}{T_{0}}\right)^{1.25} \frac{\gamma}{\operatorname{Pr}(\gamma+1)}}$,

where $D$ is the inverse Knudsen number equal to $\sqrt{\pi} h / 2 \lambda$. Figure 2 shows these non-dimensional conduction heat fluxes with air parameters in Table 1. The largest difference between the conduction heat flux predicted by Ju's model and Chen's is at an inverse Knudsen number of approximately 3.2; between Zhou's model and Chen's, it occurs when an inverse Knudsen number is about 3.0 and $T$ is $0{ }^{\circ} \mathrm{C}$. The overall relative difference between these three types of non-dimensional heat flux is less than $20 \%$.

\section{Simulation of Air Bearing Sliders with Thermal Protrusion}

This article focuses on the numerical analysis of the air bearing cooling effect and the viscous dissipation effect on

Table 1 Air parameters at different temperatures

\begin{tabular}{llll}
\hline $\begin{array}{l}\text { Temperature } \\
\left({ }^{\circ} \mathrm{C}\right)\end{array}$ & $\begin{array}{l}\text { Ratio of the } \\
\text { specific heat } \gamma\end{array}$ & $\begin{array}{l}\text { Prandtl } \\
\text { number } \operatorname{Pr}\end{array}$ & $\begin{array}{l}\text { Thermal conductivity } \\
k(\mathrm{~W} / \mathrm{m} \mathrm{K})\end{array}$ \\
\hline 0 & 1.401 & 0.713 & 0.02428 \\
25 & 1.400 & 0.707 & 0.02624 \\
50 & 1.399 & 0.701 & 0.02816 \\
75 & 1.398 & 0.697 & 0.03003 \\
\hline
\end{tabular}

the slider's static flying attitude, and numerical comparisons of different static flying attitudes obtained when different HDI heat transfer models are applied. First, Ju's model is used to analyze the effect of viscous dissipation on the slider's static attitude, as the heat conduction term and the viscous dissipation term in Ju's model are both validated by Ju's DSMC simulation results and our analytical analysis [9]. Second, the slider's static simulation results obtained with Zhang's and Chen's models, Ju's model and Zhou's model are compared to determine the difference due to modeling the air bearing cooling.

In the numerical analysis, an INSIC pico slider $(1.25 \mathrm{~mm} \times 1 \mathrm{~mm} \times 0.3 \mathrm{~mm})$ [2] and a commercial femto slider $(0.85 \mathrm{~mm} \times 0.7 \mathrm{~mm} \times 0.23 \mathrm{~mm})$ are used. The pico slider's ABS is shown in Fig. 3 and its heatingpower-off static flying attitude is shown in Table 2. The static flying height of a slider with thermal protrusion is numerically obtained using the iterative loop code developed by Juang et al. [2]. This loop contains a Reynolds equation solver for the steady-state flying of an air bearing slider and a finite-element analysis program to calculate the thermal protrusion due to inside heating, heat convection on non-air-bearing surfaces and complex heat transfer at the ABS. Here, the CML static air bearing program is used to solve the generalized Reynolds lubrication equation for the slider's static flying attitude. In the iteration, the ABS with an updated thermal protrusion profile is input into the CML program. The finite-element model for a pico slider with a giant magnetoresistive head and a micro heater developed in reference [2] is used here for the protrusion calculation in ANSYS. The heat conduction at the ABS, i.e., air bearing cooling, can be treated as heat convection 


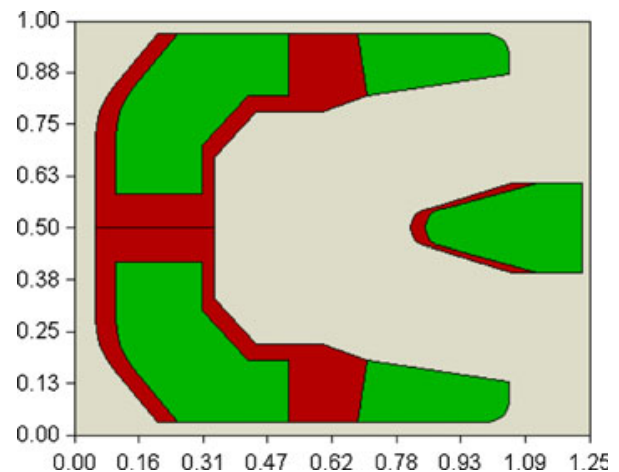

Fig. 3 Air bearing surface of an INSIC pico slider (unit: $\mathrm{mm}$ )

Table 2 Specification of the suspension used in the numerical analysis and corresponding static flying attitude of the pico slider (shown in Fig. 1) with heater power off

\begin{tabular}{ll}
\hline Suspension & Static flying attitude \\
\hline Suspension load: $0.0147 \mathrm{~N}$ & Transducer FH: $14.37 \mathrm{~nm}$ \\
Pitch torque: $-6.4 \mu \mathrm{N} \mathrm{m}$ & Pitch: $154.57 \mu \mathrm{rad}$ \\
Roll torque: $0.0 \mu \mathrm{N} \mathrm{m}$ & Roll: $0.36 \mu \mathrm{rad}$ \\
Pitch static attitude: $0.0 \mathrm{rad}$ & \\
Roll static attitude: $0.0 \mathrm{rad}$ & \\
\hline
\end{tabular}

at the ABS with given convection coefficients in ANSYS. As the boundary conditions of heat flux and heat convection cannot be applied to the same boundary in ANSYS, the viscous dissipation flux is treated as surface heating on the ABS, which has an areal heat generation rate twice the viscous heating flux.

The commercial femto slider's ABS is shown in Fig. 4. Due to the lack of an accurate ANSYS model for the read/ write transducer, heater, and other components in this femto slider, the structures of the read/write transducer and micro heater used in reference [2] are scaled down and adapted in the simulation of this femto slider. The same loop is used to obtain the femto slider's static flying attitude with different HDI heat transfer models.

\subsection{Viscous Dissipation Versus Air Bearing Cooling}

Ju's model is applied in the loop to analyze the effect of viscous dissipation on the slider's static flying attitude. Table 3 shows the simulation results for 40,80 , and $120 \mathrm{~mW}$ heating power of the micro-heater using Ju's model with and without the viscous dissipation contributed by Couette flow. It is obvious that the viscous dissipation effect is negligible, even when the flying height is below $2 \mathrm{~nm}$. All of the current HDI heat transfer models predict that the viscous dissipation contributed by Poiseuille flow is of the same order as that contributed by Couette flow $[3,4,7,9]$. So, it is reasonable to expect that the total

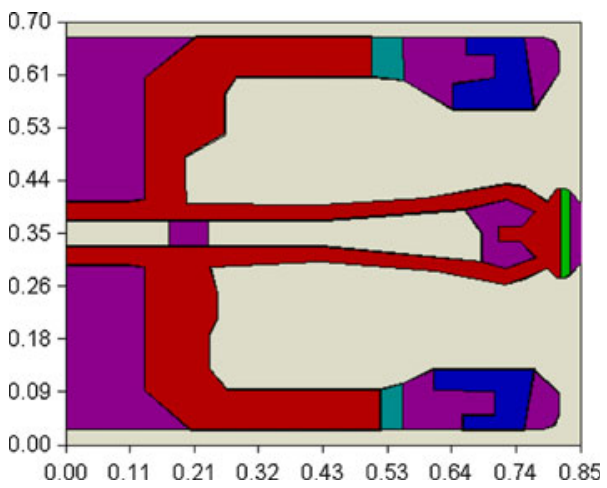

Fig. 4 Air bearing surface of a commercial femto slider (unit: $\mathrm{mm}$ )

Table 3 Static flying attitudes of the pico slider (shown in Fig. 1) obtained with and without the viscous heating contributed by Couette flow

\begin{tabular}{lccl}
\hline Heating power & \multicolumn{2}{l}{ Ju's model } & \multicolumn{2}{l}{$\begin{array}{l}\text { Zhang's and } \\
\text { Chen's models }\end{array}$} \\
\cline { 2 - 3 } & $\begin{array}{l}\text { With } \\
\text { viscous } \\
\text { heating }\end{array}$ & $\begin{array}{c}\text { Without } \\
\text { viscous } \\
\text { heating }\end{array}$ & \\
& & & \\
\hline $40 \mathrm{~mW}$ & 8.51 & 8.51 & 8.35 \\
Transducer FH (nm) & 149.56 & 149.56 & 149.18 \\
Pitch $(\mu \mathrm{rad})$ & 0.0679 & 0.0678 & 0.10 \\
Roll $(\mu \mathrm{rad})$ & & & \\
$80 \mathrm{~mW}$ & 4.21 & 4.23 & 4.00 \\
Transducer FH $(\mathrm{nm})$ & 143.94 & 144.00 & 143.30 \\
Pitch $(\mu \mathrm{rad})$ & -0.327 & -0.244 & -0.23 \\
Roll $(\mu \mathrm{rad})$ & & & \\
$120 \mathrm{~mW}$ & 1.77 & 1.75 & 1.60 \\
Transducer FH $(\mathrm{nm})$ & 137.18 & 137.19 & 136.07 \\
Pitch $(\mu \mathrm{rad})$ & -0.80 & -0.83 & -0.84 \\
Roll $(\mu \mathrm{rad})$ & & & \\
\hline
\end{tabular}

viscous dissipation of the air bearing flow at the ABS has a negligible effect on the flying attitude of this thermally actuated pico slider.

\subsection{Heat Conduction in Ju's Model Versus Zhang's and Chen's Models}

The only difference between the heat conduction part in Ju's model and that in Zhang's and Chen's models is that the surface thermal accommodation coefficient is 1.0 in Ju's model, while it is a parameter in Zhang's and Chen's models. For the slider and disk surface, the thermal accommodation coefficient is chosen as 0.9 in Zhang's and Chen's models. Here, simulations are carried out for three values of heating powers, 40, 80, and $120 \mathrm{~mW}$. Table 3 lists the slider's static flying attitude obtained using Ju's model and with Zhang's and Chen's models. The relative 
differences in the static transducer $\mathrm{FH}$ and pitch angle increase with the heating power. However, it is approximately $9 \%$ in the flying height and less than $1 \%$ in the pitch angle, even when the flying height is reduced to below $2 \mathrm{~nm}$. The difference in the static roll angle is less than $1 \mu \mathrm{rad}$ and thus negligible, although it is large compared with $1 \mu \mathrm{rad}$ level roll angle. The difference here due to the choice of the thermal accommodation coefficient value is larger than the difference due to considering or neglecting the Couette-flow-caused viscous heating in Ju's model. This indicates that the surface thermal accommodation coefficient has a larger effect than the Couette-flow-caused viscous heating in the HDI heat transfer.

\subsection{Heat Conduction in Zhou's Model Versus Zhang's and Chen's Models}

The difference between Zhou's model and Zhang's and Chen's models is that the dependence of the mean free path of the air molecules on the ambient temperature is considered in Zhou's model. Here, simulations are carried out for different ambient temperatures. The air parameters used in the models, including the ratio of the specific heat,
Prandtl number, and thermal conductivity, change as the air temperature changes. Table 1 lists those parameter values for the air temperatures of $0,25,50$, to $75^{\circ} \mathrm{C}$. Using those values in Zhou's model or Zhang's and Chen's models, the slider's static flying attitudes are obtained and listed in Table 4, when the heating power is 40 and $80 \mathrm{~mW}$, respectively. It is obvious that as the ambient temperature increases, the air cooling effect on the slider's surface, including the ABS and non-ABS, decreases if the convection and conduction coefficients do not change much. On one hand, this leads to an increase in the slider's temperature and thermal protrusion at the trailing edge center. The increased thermal protrusion causes flying height loss. On the other hand, a flying slider with decreased air cooling will be less affected by the modeling difference of the air cooling in the simulation. Zhou's model and Chen's model differ most at the temperature of $0{ }^{\circ} \mathrm{C}$ and least at $75{ }^{\circ} \mathrm{C}$, as shown in Fig. 2. Therefore, the greatest difference between the slider static flying attitudes obtained from Zhou's model and Chen's model occurs at the temperature of $0{ }^{\circ} \mathrm{C}$ and a heating power of $80 \mathrm{~mW}$ in Table 4. The greatest relative difference in the static transducer $\mathrm{FH}$ is less than $7 \%$ and pitch angle is less than
Table 4 Static flying attitudes of the pico slider (shown in Fig. 1) obtained with Zhou's model and with Zhang's and Chen's models

\begin{tabular}{|c|c|c|c|c|}
\hline $\begin{array}{l}\text { Heating } \\
\text { power }\end{array}$ & $\begin{array}{l}\text { Ambient } \\
\text { temperature }\left({ }^{\circ} \mathrm{C}\right)\end{array}$ & Flying attitude & Zhou's model & $\begin{array}{l}\text { Zhang's and } \\
\text { Chen's models }\end{array}$ \\
\hline \multirow[t]{12}{*}{$40 \mathrm{~mW}$} & \multirow[t]{3}{*}{0} & Transducer FH (nm) & 9.47 & 9.20 \\
\hline & & Pitch $(\mu \mathrm{rad})$ & 148.91 & 148.41 \\
\hline & & Roll ( $\mu \mathrm{rad})$ & 0.079 & -0.014 \\
\hline & \multirow[t]{3}{*}{25} & Transducer FH (nm) & 8.44 & 8.36 \\
\hline & & Pitch $(\mu \mathrm{rad})$ & 149.49 & 149.21 \\
\hline & & Roll ( $\mu \mathrm{rad})$ & 0.036 & 0.011 \\
\hline & \multirow[t]{3}{*}{50} & Transducer FH (nm) & 7.31 & 7.22 \\
\hline & & Pitch $(\mu \mathrm{rad})$ & 149.47 & 149.45 \\
\hline & & Roll ( $\mu \mathrm{rad})$ & 0.096 & 0.066 \\
\hline & \multirow[t]{3}{*}{75} & Transducer FH (nm) & 5.87 & 5.87 \\
\hline & & Pitch $(\mu \mathrm{rad})$ & 148.48 & 148.60 \\
\hline & & Roll $(\mu \mathrm{rad})$ & 0.011 & 0.096 \\
\hline \multirow[t]{12}{*}{$80 \mathrm{~mW}$} & \multirow[t]{3}{*}{0} & Transducer FH (nm) & 5.08 & 4.76 \\
\hline & & Pitch $(\mu \mathrm{rad})$ & 143.35 & 142.39 \\
\hline & & Roll ( $\mu \mathrm{rad})$ & -0.26 & -0.34 \\
\hline & \multirow[t]{3}{*}{25} & Transducer FH (nm) & 4.16 & 4.01 \\
\hline & & Pitch $(\mu \mathrm{rad})$ & 143.85 & 143.39 \\
\hline & & Roll ( $\mu \mathrm{rad})$ & -0.27 & -0.23 \\
\hline & \multirow[t]{3}{*}{50} & Transducer FH (nm) & 3.36 & 3.28 \\
\hline & & Pitch $(\mu \mathrm{rad})$ & 144.35 & 144.15 \\
\hline & & Roll ( $\mu \mathrm{rad})$ & -0.36 & -0.26 \\
\hline & \multirow[t]{3}{*}{75} & Transducer FH (nm) & 2.29 & 2.33 \\
\hline & & Pitch $(\mu \mathrm{rad})$ & 143.18 & 143.21 \\
\hline & & Roll $(\mu \mathrm{rad})$ & -0.43 & -0.34 \\
\hline
\end{tabular}


Fig. 5 Logarithm of the inverse Knudsen number on the pico ABS at $25^{\circ} \mathrm{C}$
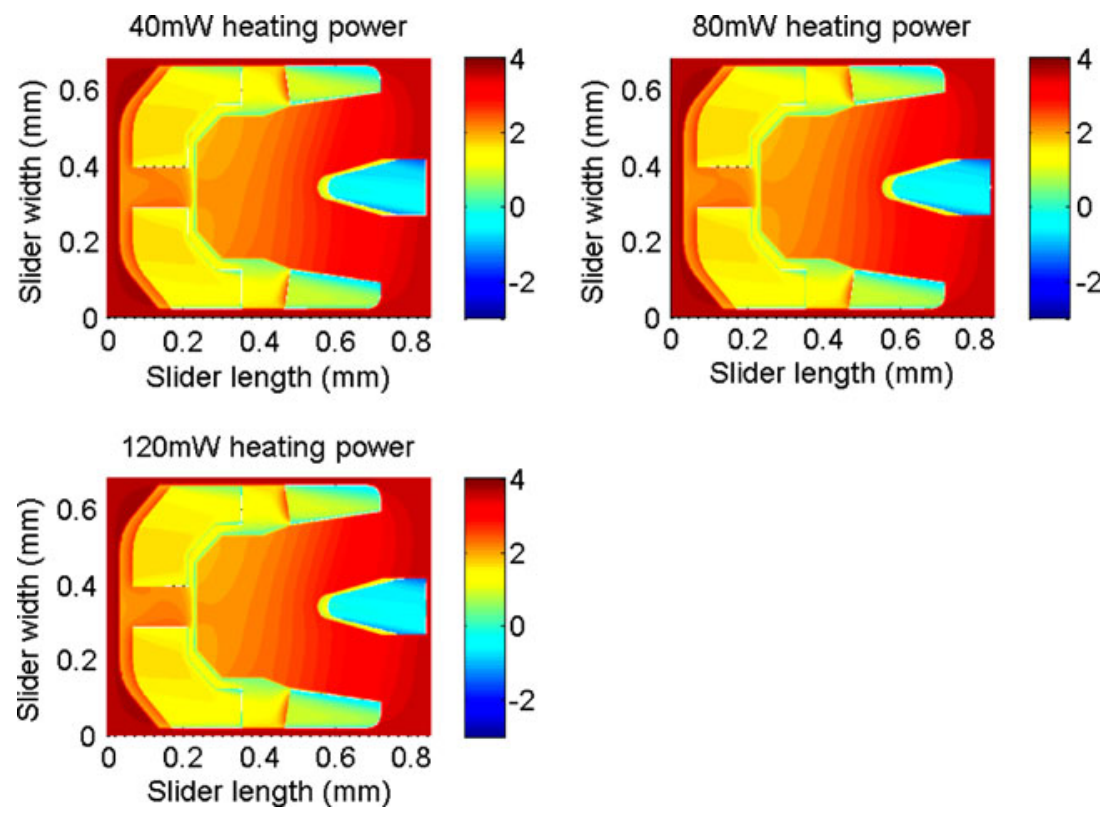

$1 \%$. Similarly, although the relative difference in the static roll angle is larger than $10 \%$, the absolute difference is still less than $1 \mu \mathrm{rad}$ and is negligible.

The thermal-mechanical system of the air bearing slider with thermal actuation is highly nonlinear. However, it is seen here that the different air bearing models do not cause an essential difference in the slider's static flying attitudes. This is related to the fact that the inverse Knudsen numbers on the air bearing surface are distributed in a wide range. The natural logarithm of the local inverse Knudsen number on the ABS is plotted in Fig. 5. It is seen that the inverse Knudsen number ranges between 0.01 and 55. On the trailing pad, the inverse Knudsen number is less than 1. The result is that the modeling difference of the air bearing cooling is insignificant on most of the air bearing surface.

The assumption of isothermal flow may not apply locally as the air bearing cooling becomes weak. As analyzed in the above, the heat conduction on the ABS decreases as the ambient temperature increases. Then the temperature rise $\left(T_{\mathrm{s}}-T_{\mathrm{d}}\right)$ on the ABS due to TFC increases as the air temperature increases in the drive. This can be seen from Fig. 6, the ABS temperature rise obtained using Zhang's and Chen's models. With the same TFC heating power $(80 \mathrm{~mW})$, the temperature rise on the ABS with an ambient air temperature of $25^{\circ} \mathrm{C}$ is much less than that with $75^{\circ} \mathrm{C}$ ambient air. As expected and shown in Fig. 6, the maximum temperature rise is only around the transducer and the micro heater. The maximum value of $\left(T_{\mathrm{s}}-T_{\mathrm{d}}\right) / T_{\mathrm{d}}$ is $4.7 \%$ when $T_{\mathrm{d}}=25^{\circ} \mathrm{C}$ and it is $17.8 \%$ when $T_{\mathrm{d}}=75^{\circ} \mathrm{C}$. In these two cases, we still have $\left(T_{\mathrm{s}}-\right.$ $\left.T_{\mathrm{d}}\right) \ll T_{\mathrm{d}}$ and the assumption of isothermal air bearing flow is still valid. However, as the temperature rise on the ABS increases further and its maximum value becomes

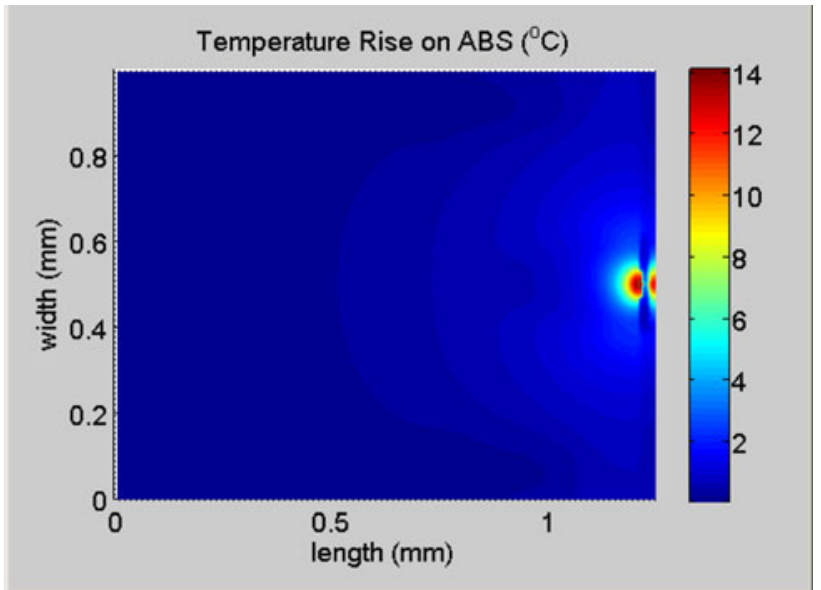

(a) Temperature rise on the ABS when $T_{d}=25^{\circ} \mathrm{C}$

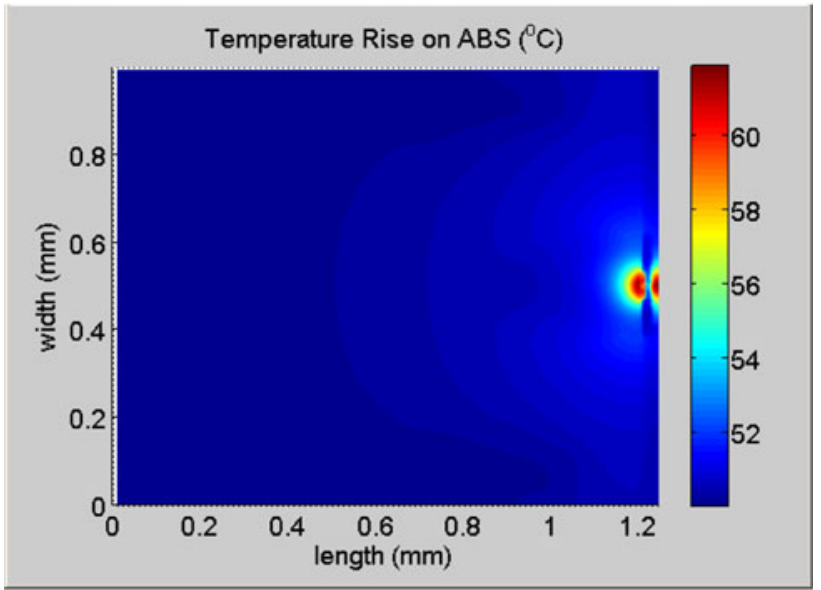

(b) Temperature rise on the ABS when $T_{d}=75^{\circ} \mathrm{C}$

Fig. 6 Temperature rise on the ABS (in Fig. 3) when a TFC heating power of $80 \mathrm{~mW}$ obtained using Zhang's and Chen's models 
Table 5 Static flying attitudes of the Femto slider (shown in Fig. 2) obtained with different HDI heat transfer models

\begin{tabular}{|c|c|c|c|c|c|c|}
\hline \multirow{2}{*}{$\begin{array}{l}\text { Heating } \\
\text { power }\end{array}$} & \multirow[t]{2}{*}{ Flying attitude } & \multicolumn{2}{|l|}{ Ju's model } & \multirow{2}{*}{$\begin{array}{l}\text { Zhang's and Chen's } \\
\text { models } \\
\text { Without viscous } \\
\text { heating }\end{array}$} & \multirow{2}{*}{$\begin{array}{l}\text { Zhou's model } \\
\text { with } 75^{\circ} \mathrm{C} \\
\text { Without viscous } \\
\text { heating }\end{array}$} & \multirow{2}{*}{$\begin{array}{l}\text { Zhang's and Chen's } \\
\text { models with } 75^{\circ} \mathrm{C} \\
\text { Without viscous } \\
\text { heating }\end{array}$} \\
\hline & & $\begin{array}{l}\text { With viscous } \\
\text { heating }\end{array}$ & $\begin{array}{l}\text { Without viscous } \\
\text { heating }\end{array}$ & & & \\
\hline \multirow[t]{3}{*}{$200 \mathrm{~mW}$} & Transducer FH (nm) & 9.15 & 9.11 & 8.99 & 7.68 & 7.71 \\
\hline & Pitch $(\mu \mathrm{rad})$ & 103.65 & 103.81 & 103.26 & 103.45 & 103.70 \\
\hline & Roll ( $\mu \mathrm{rad})$ & -25.76 & -25.58 & -25.71 & -26.15 & -26.08 \\
\hline
\end{tabular}

comparable to the ambient air temperature (which equals to $T_{\mathrm{d}}$ ), the assumption of isothermal flow will break down locally. Then, both the air bearing cooling model and the air bearing model need to take the non-isothermal condition into considerations. However, for a typical air bearing slider with TFC, as shown in Fig. 3 or 4, the assumption of isothermal flow usually holds even when the slider's thermal protrusion contacts the disk.

\section{Simulation Results for Static Flying Attitude of a Femto Slider}

A heating power of $200 \mathrm{~mW}$ is used in the simulation of the commercial femto slider, whose ABS is shown in Fig. 4. Usually $200 \mathrm{~mW}$ is beyond its practical working power. Table 5 lists the static flying attitudes of the femto slider with different heat transfer models. It is obvious that the flying attitudes obtained with Ju's model with and without Couette-flow-caused viscous heating, and Zhang's and Chen's models are almost the same. At the ambient temperature of $75{ }^{\circ} \mathrm{C}$, the static flying attitudes obtained with Zhou's model and Zhang's and Chen's model are also very close. The largest difference is not more than $2 \%$ when compared with the results obtained with Zhang's and Chen's models.

\section{Conclusion}

Numerical simulations for the static flying attitudes of air bearing sliders with thermal protrusion are carried out using different head-disk-interface heat transfer models. The air bearing cooling effect is found to be dominant at the air bearing surface compared with the viscous dissipation due to Couette flow. As the viscous dissipation contributed by Poiseuille flow is no larger than the viscous dissipation contributed by Couette flow, it is expected that the entire viscous dissipation has an insignificant effect on the static flying attitude of flying sliders.
The change of surface thermal accommodation coefficient from 1.0, which is used in Ju's model [4], to 0.9, which is recommended in Zhang's and Chen's models [3, 7] for the slider and disk surfaces, causes a difference less than $9 \%$ in the static transducer flying height and less than $1 \%$ in the pitch angle. The consideration of the temperature-dependence of the air molecule's mean free path in Zhou's model gives a relative difference less than $7 \%$ in the static transducer flying height when compared with Zhang's and Chen's models. This difference becomes smaller at a higher drive temperature and lower heater power. However, when an allowable dynamic fly height modulation with an amplitude of approximately $10 \%$ of the flying height is considered, Zhang's model (or Chen's model), which is used in the simulation by Juang et al. [2], is accurate enough for the static flying attitude simulation of an air bearing slider with thermal protrusion.

Acknowledgment This research was supported by the Information Storage Industry Consortium (INSIC) and the Computer Mechanics Laboratory (CML) at the University of California at Berkeley.

Open Access This article is distributed under the terms of the Creative Commons Attribution Noncommercial License which permits any noncommercial use, distribution, and reproduction in any medium, provided the original author(s) and source are credited.

\section{References}

1. Meyer, D.W., Kupinski, P.E., Liu, J.C.: U.S. Patent No. 5991113 (1999)

2. Juang, J.Y., Chen, D., Bogy, D.B.: Alternate air bearing slider designs for areal density of 1 Tbit/in ${ }^{2}$. IEEE Trans. Magn. 42, 241246 (2006)

3. Chen, L., Bogy, D.B., Strom, B.: Thermal dependence of MR signal on slider flying state. IEEE Trans. Magn. 36, 2486-2489 (2000)

4. Ju, Y.S.: Thermal conduction and viscous heating in Microscale Couette flows. ASME J. Heat Transf. 122, 817-818 (2000)

5. Zhou, W.D., Liu, B., Yu, S.K., Hua, W., Wong, C.H.: A generalized heat transfer model for thin film bearings at headdisk interface. Appl. Phys. Lett. 92, 043109 (2008)

6. Shen, S., Chen, G.: A kinetic theory analysis on the heat transfer in hard drive air bearing. J. Appl. Phys. 103, 054304 (2008) 
7. Zhang, S., Bogy, D.B.: A heat transfer model for thermal fluctuation in a thin air bearing. Int. J. Heat Mass Transf. 42, 1791-1800 (1997)

8. Bird, G.A.: Molecular Gas Dynamics and the Direct Simulation of Gas Flows, 1st edn. Oxford University Press, New York (1994)
9. Chen, D., Liu, N., Bogy, D.B.: A phenomenological heat transfer model for the molecular gas lubrication system in hard disk drives. J. Appl. Phys. 105, 084303 (2009) 